\title{
Prevalence and Associated Risk Factors of Gastrointestinal Nematodes of Sheep and Goats in ZiwayDugda District, Eastern Arsi Zone of Oromia Regional State, Ethiopia
}

\author{
Jiregna Dugassa*, Abdela Hussein, Abriham Kebede, Chala Mohammed \\ Wollega University, School of Veterinary Medicine, College of Medical and Health Sciences, P.O. Box, 395, \\ Nekemte, Ethiopia
}

*Corresponding Author: Jiregna Dugassa, Wollega University, School of Veterinary Medicine, College of Medical and Health Sciences, P.O.Box, 395, Nekemte, Ethiopia. Email:Jiregnadu@gmail.com

\begin{abstract}
A cross sectional study was conducted in sheep and goats that were kept under extensive management system in ZiwayDugda District, Eastern Arsi Zone, Oromia Regional State from November, 2016 G.C to April, 2017 G.C to determine prevalence and associated risk factors of GI nematodes. A total of 384 randomly sampled sheep and goats (281 sheep and 103 goats) were undergone coprological examination by simple floatation and McMaster egg counting technique. In the study areas, the overall prevalence of GIT nematodes in sheep and goats was $71.88 \%$ (276/384). Out of the total sampled animals, the prevalence of $75.8 \%$ (213/281) and 61.2\% (63/103) were recorded in sheep and goats respectively. Based on coprological examination, in the study area, the prevalence of $54.17 \%, 8.33 \%, 3.13 \%$ and $6.25 \%$ accounted for Strongyle, Strongyloide, Trichuris and mixed type of infection between both species respectively. McMaster egg counting of positive samples revealed $42 \%, 33.7 \%$ and $24.3 \%$ as light, moderate and severe respectively. Species, age, sex and PAs of the animals were not shown statistically significant association $(P>0.05)$ with prevalence of GIT nematodes. Body condition score of the animals has shown statistically significant difference $(P<0.05)$. In general, high prevalence of nematode parasites was observed in the study area, which implies nematodes are the major constraints for production and productivity of these animals. Therefore, economically feasible, effective management and strategic de-worming of animals should be implemented for the prevention and control of the disease.
\end{abstract}

Keywords: Goats, Nematodes, Prevalence, Sheep, ZiwayDugda district

\section{INTRODUCTION}

Livestock production constitutes one of the principal means of achieving improved living standards in many regions of the developing world. In Sub-Saharan African countries, livestock plays a crucial role both on national economies and the livelihood of rural communities. It provides drought power, milk, and meat, input for crop production and soil fertility and raw material for industry. Various estimate shows that the livestock sector contributes $13-16 \%$ of total agricultural GDP [1] and is becoming the fastest growing subsector of agriculture [2]. Small ruminant farming has a prominent role in the sustainability of rural communities around the world [3] as well as being socially, economically and politically highly significant at national and international levels, similar to other livestock species [4].

ARC Journal of Animal and Veterinary Sciences
Sheep and goats have great importance as major sources of livelihood and contribute to the sustenance of landless, smallholder and marginal farmers especially to the poor in the rural areas throughout the developing countries. Studies have revealed that ruminants contribute $80 \%$ of the total food production from livestock in tropical Africa, of which small ruminants account for about $22 \%$. Sheep and goats are also very important for resource-poor smallholder systems of rural Ethiopia due to their ease of management, short generation cycles and high reproductive rates which lead to high production efficiency and significant role in provision of food and generation of cash income. They serve as a living bank for many farmers, closely linked to the social and cultural life of resource poor farmers and provide security in bad crop years [5].

Generally, Small ruminants are important source of the developing country as they provide more 
than $30 \%$ of local meat consumption and generate cash income from the export of meat, live animals and skins [6]. These small ruminants were estimated to 24 million sheep and 18 million goats constitute a major part of livestock resource. From this annual national mutton and goat meat production is 77 and 62 thousand metric ton, respectively. These animals contribute $13.9 \%$ and 11.2 of the total meat production. The share of small ruminants of the total milk output is estimated to $16.4 \%$ and Ethiopia exports 155,000 heads of livestock particularly sheep and goats annually [7].

Gastrointestinal (GI) nematode parasites are a major problem in most small ruminant production systems worldwide due to their impact on production and the cost of control measures undertaken by livestock producers. The problem of nematode parasitism is of particular importance throughout the developing world since nutritional resources available to small ruminant livestock are often inadequate and, as a consequence, natural immunity is compromised resulting in low productivity and high mortality [8].

Due to suitable geographic and climatic conditions of the country, parasitic GI nematodes are perhaps the leading cause of productivity losses in small ruminant production in Ethiopia [9]. Parasitological investigations carried out in different regions of the country have demonstrated the existence of a wide range of GI nematodes which belong to the genera of Haemonchus, Trichostrongylus, Oesophagostomum, Bunostomum, Strongyloides, Cooperia, Bunostomum, Nematodirus and Trichuris[10,11]. Most of these parasites are shared by both sheep and goats. However, the prevalence of GIT parasites, the genera of nematode parasites involved and the severity of infection vary considerably from region to region, corresponding to ecological and climatic diversity in the country [9].

Small holders and pastoralists may not easily detect the effect of helminths because of the subclinical nature of the infections [12, 13]. Thus, the sub-clinical nematode infections are responsible for significant economic losses. They are responsible for immune-suppression and enhancing the susceptibility of the animals to other diseases. Once the clinical diseases are noticed, such economic losses in terms of animal productivity have already occurred [14]. In Ethiopia productivity losses due to helminth parasites are often substantial and a loss of US $\$ 81.8$ million is reported annually [15].

Management of parasites, gastrointestinal worms in particular, is often a primary animal health issue on many farms and ranches. Our tropical environment is an ideal habitat for parasite species, especially in wetter locations. Losses caused by heavy parasite burdens are both direct, in terms of death, poor gains and reproductive inefficiency and indirect, stemming from increased susceptibility to secondary infection and greater labor needs. Parasite control should form a central part of every small ruminant health management strategy. Which is a major element in ensuring the sustainability of sheep and goat production is currently achieved by the use of anthelmintics[16].

Prevalence of GIT nematodes vary in diverse geographical conditions and influenced by climate, management, vegetation and livestock density [17]. In many parts of Ethiopia considerable amount of researches have been carried outby different researchers to investigate prevalence and intensity of nematode infection in small ruminants. The researches carried out around DebreZeit, ArsiNegele, Haramaya and Western Hararge by [18, 19,20,21] showed prevalence of GI nematodes as being $86.7 \%$, $69.01 \%, 88.8 \%$ and $50.8 \%$ respectively. In the district, the main form of agricultural practice is mixed (crop-livestock) production system where people mostly focus on crop production which leaves small area (marginal land, swampy and mountain) for grazing of animals. Even though gastrointestinal nematodes are a major problem causing loss of production and productivity in sheep and goats of the area, there was no research conducted in the study area. Therefore, the objective of this study was:

- To determine the prevalence and intensity of gastrointestinal nematodes in sheep and goats and its associated risk factors.

\section{Materials And Methods}

\subsection{Study Area}

The Present Study was conducted from November, 2016 G.C to April, 2017 G.C in five (5) Peasant associations namely: Golbe, Sango, Burka Lamafo, Sambaro and Ogolcho of ZiwayDugda District, East Arsi Zone of Oromia Regional State, Ethiopia. The area is located 221 $\mathrm{km}$ south East of Addis Ababa, the capital city of the country and $46 \mathrm{~km}$ from Asella the capital 
city of East Arsi zone. The district is located in the Rift Valley Region. ZiwayDugda district has an area of $1269.07 \mathrm{~km}^{2}$, having a population of 120121 with about 94.7population density. Of $1269.07 \mathrm{~km}^{2}$ area of the district: $31.7 \%$ is arable or used for crop cultivation, $6 \%$ of pasture, $46.3 \%$ forest and the remaining $16 \%$ is swampy, mountainous or unusable. Estimated animal population in the area is about 124,680 cattle, 24,524 sheep, 40,286 goats, 17,851 equines and 60,345 chickens. Topographically, the district is tropical in nature located at an altitude of 1600 $1800 \mathrm{~m}$ above sea level with the minimum and maximum temperature $19^{\circ} \mathrm{C}$ and $32^{\circ} \mathrm{C}$ respectively. The district receives an average annual rainfall ranges between $650-800 \mathrm{~mm}$, with bimodal rainfall March to April (short rainy season) and July to October (long rainy season) [22].

\subsection{Study Animals}

The study subjects include all grazing sheep and goats of all different age, sex and body conditions kept under extensive management system from selected PAs of Ziway Dugda district.

\subsection{Study Design}

A cross-sectional study was used to determine the prevalence of GIT nematodes in sheep and goats based on coprological examination.

\subsection{Sampling Methods and Sample Size Determination}

The sample size was determined by the formula described by [23]. Accordingly, it was set at 95\% Confidence level and precision of 5\% so that the total sample size was determined to be 384. Since there was no research carried out previously in the study area, the expected 50\% prevalence was taken. Five peasant associations were purposively selected based on accessibility as well as availability of the livestock potential (sheep and goats) with various proportions of samples from each five PAs.

$$
\begin{aligned}
& \mathrm{n}=1.96 \mathrm{6} \times \mathrm{xpexp}(1-\mathrm{pexp})=1.96 \cdot \mathrm{6} \times 0.5(1-0.5)=384 \text { sheep and goats } \\
& d^{2} \quad(0.05)^{2}
\end{aligned}
$$

Where: $\mathrm{n}=$ sample size required

$\mathrm{P}_{\text {exp }}=$ expected prevalence $=50 \%$

$1.96=$ the value of $Z$ at $95 \%$ confidence interval

$\mathrm{d}=$ desired level of precision at $95 \%$ confidence interval

ARC Journal of Animal and Veterinary Sciences

\subsection{Study Methodology}

The samples were collected from different sex, age and body condition from various PAs of study areas. Age was determined for both sexes based on dentition. Those animals with the age of less than one year were considered as young while those greater than or equal to one were considered as adults according to the classification of age groups by [24]. Body condition scoring of sampled animals were carried out according to the method described by [25] and categorized into three scores as poor, medium and good.

\section{Parasitological Study}

A sample was collected directly from the rectum of sheep and goats using hand gloves. Each sample was clearly labeled with animal identification, date and place of collection. The faecal samples were placed in a universal bottle, labeled and $10 \%$ formalin was added to preserve parasite eggs and transported toAsella Regional Veterinary laboratory, Parasitology laboratory unit to detect eggs of nematode parasites. Those samples which were not examined within 24 hour of arrival at laboratory were stored at $+4^{\circ} \mathrm{C}$ and examined the next day early in the morning. The collected samples were subjected to qualitative flotation and quantitative McMaster egg counting parasitological techniques using saturated sodium chloride (specific gravity of 1.2) as flotation fluid. The eggs of parasite species were identified using keys given by [26] Samples that became positive for gastrointestinal nematode were subjected to EPG counting to determine the number of egg per gram of feces (EPG) and performed according to the procedure described [13]. The degree of infection was categorized as light, moderate and severe (massive) according to their egg per gram of faeces (EPG) counts. Egg counts from 50-799, 800-1200 and over 1200 eggs per gram of feces were considered as light, moderate and (severe) massive infection, respectively [12].

\subsection{Data Management and Analysis}

The raw data was entered into Microsoft excel spread sheet, coded and analyzed using Statistical Package for Social Students (SPSS) version 20.0 Statistical software. Descriptive statistics were used to quantify the problems and Chi-square test was used to compare association between independent variables (sex, age, body condition scores) with the result. Confidence 
Prevalence and Associated Risk Factors of Gastrointestinal Nematodes of Sheep and Goats in ZiwayDugda District, Eastern Arsi Zone of Oromia Regional State, Ethiopia

interval was set at 95\% and with 5\% degree of precision. Statistically significant association between variable was considered to be exist if the computed P-value is less than 0.05.

\section{RESUlts}

Out of 384 small ruminants sampled in the study, 281 sheep and 103 goats were examined for GIT nematode infections. In the present study, the coprological examination revealed an overall prevalence of $71.88 \%$ (276/384) for gastrointestinal nematode infection in both sheep and goats. Specifically, the prevalence of
$75.8 \%$ (213/281) with various GIT nematode infections was recorded in sheep and similarly $61.2 \%(63 / 103)$ was recorded in goats. Of all the sheep and goat examined in the five PAs, samples from Golbe 76/103(73.8\%) showed the higher GIT nematodes prevalence and the samples from Ogolcho 01 64/92(69.6\%) showed low infection prevalence record. There was no statistically significant difference, $(\mathrm{P}=0.997)$ in prevalence of gastrointestinal nematode infection of sheep and goats between the five PAs (Burka lamafo, Golbe, Ogolcho, Sambaro and Sango) and briefly summarized in (Table 1).

Table1. Prevalence of GIT nematodes in sheep and goats selected PAs

\begin{tabular}{|l|c|c|c|c|}
\hline PAs & No of examined samples & No of positive (\%) & $\boldsymbol{\chi} \mathbf{2}$ & P-value \\
\hline Burka Lamafo & 78 & $55(70.5)$ & & \\
\hline Golbe & 103 & $76(73.8)$ & & \\
\hline Ogolcho 01 & 92 & 9.369 & $64(69.6)$ & 0.997 \\
\hline Sambaro & 51 & $37(72.5)$ & & \\
\hline Sango & 60 & $44(73.3)$ & & \\
\hline Total & $\mathbf{3 8 4}$ & $\mathbf{2 7 6}(\mathbf{7 1 . 8 8})$ & & \\
\hline
\end{tabular}

(Note: $\chi^{2}=$ chi square)

The predominant GIT nematodes identified in sheep and goats in the study area were Strongyle, Strongyloides and Trichuris with prevalence of $54.17 \%, 8.33 \%$ and $3.13 \%$

respectively. Mixed nematode eggs were also examined in some of the slides beside the single type of nematode eggs, with a prevalence of $6.25 \%$ in sheep and goats (Table 2 ).

Table2. Prevalence of GIT nematode of small ruminants with egg type

\begin{tabular}{|l|l|l|}
\hline Type of eggs & No. of examined samples & No. of Positive (\%) \\
\hline Strongyle & $\mathbf{3 8 4}$ & $\mathbf{2 0 8}(\mathbf{5 4 . 1 7})$ \\
\hline Strongyloide & $\mathbf{3 8 4}$ & $\mathbf{3 2 ( 8 . 3 3 )}$ \\
\hline Trichuris & $\mathbf{3 8 4}$ & $\mathbf{1 2 ( 3 . 1 3 )}$ \\
\hline Mixed type of eggs & $\mathbf{3 8 4}$ & $\mathbf{2 4 ( 6 . 2 5 )}$ \\
\hline Total & $\mathbf{3 8 4}$ & $\mathbf{2 7 6 ( 7 1 . 8 8 )}$ \\
\hline
\end{tabular}

During the study period prevalence was assessed between the risk factors. Accordingly, $73.1 \%$ and $67.1 \%$ in females and males, $72.9 \%$ and $71.3 \%$ in young and adult

Table3. Prevalence of small ruminant gastrointestinal nematodes by sex, age and Body Condition Score

\begin{tabular}{|c|c|c|c|c|c|}
\hline & & № examined & $\begin{array}{l}\text { No of Positive } \\
(\%)\end{array}$ & $\chi^{2}$ (P-value) & $95 \% \mathrm{CI}$ \\
\hline \multirow[t]{3}{*}{ Species } & Sheep & 281 & $213(75.8)$ & \multirow[t]{2}{*}{$10.609(0.101)$} & \multirow[t]{2}{*}{ 0.078-0.141 } \\
\hline & Goat & 103 & $63(61.2)$ & & \\
\hline & Total & 384 & 276(71.88) & & \\
\hline \multirow[t]{3}{*}{ Age } & Young & 144 & $105(72.9)$ & \multirow[t]{2}{*}{$8.851(0.182)$} & \multirow[t]{2}{*}{ 0.153-0.232 } \\
\hline & Adult & 240 & 171(71.3) & & \\
\hline & Total & 384 & 276(71.88) & & \\
\hline \multirow[t]{3}{*}{ Sex } & Male & 79 & $53(67.1)$ & \multirow[t]{2}{*}{5.081() 0.534} & \multirow[t]{2}{*}{$0.468-0.568$} \\
\hline & Female & 305 & $223(73.1)$ & & \\
\hline & Total & 384 & $276(71.88)$ & & \\
\hline \multirow[t]{3}{*}{$\overline{\mathrm{BCS}}$} & Poor & 166 & $128(77.1)$ & \multirow[t]{3}{*}{$21.132(0.048)$} & \multirow[t]{3}{*}{$0.016-0.052$} \\
\hline & Medium & 100 & 7.(70.0) & & \\
\hline & Good & 118 & $78(66.1)$ & & \\
\hline & Total & 384 & $276(71.88)$ & & \\
\hline
\end{tabular}

In this study, evaluation was made to appreciate the effect of sex on disease prevalence. Females

ARC Journal of Animal and Veterinary Sciences were revealed respectively. Similarly, $77.10 \%$, $70 \%$ and66.10\% in poor, medium and good body condition respectively (Table 3 ) and males were found to be infested with a variable degree but without significant variation 
Prevalence and Associated Risk Factors of Gastrointestinal Nematodes of Sheep and Goats in ZiwayDugda District, Eastern Arsi Zone of Oromia Regional State, Ethiopia

$(\mathrm{P}>0.05)$. Accordingly, higher prevalence of GI nematode infection was observed in female animals $(73.1 \%)$ as compared to males $(67.1 \%)$ between the two sexes (Table 3). Young and adult animals were found to be infested with a prevalence of $72.9 \%$ and $71.3 \%$, respectively but there is also no statistically Significant difference $(\mathrm{P}>0.05)$ (Table 3). The prevalence of GIT nematode with respect to different body condition scores of the study animals was also presented in (Table 3). Slightly higher prevalence of nematode infection was observed

Table4. Burden of infection according to EPG count for in poor body condition animals (77.1\%) followed by medium $(70.0 \%)$ and good (66.1\%) body conditioned animals with a statistically significant difference $(\mathrm{P}<0.05)$.

A total of 276 fecal samples that were positive by qualitative parasitological techniques were subjected to EPG count using McMaster egg counting technique. Accordingly, 116(42.0\%), $93(33.7 \%)$ and $67(24.3 \%)$ were found to be lightly, moderately and severely infected respectively (Table 4).

\begin{tabular}{|l|l|l|l|}
\hline Level of infection & frequency & Prevalence & EPG \\
\hline Light & $\mathbf{1 1 6}$ & $\mathbf{4 2 . 0 \%}$ & $\mathbf{5 0 - 7 9 9}$ \\
\hline Moderate & $\mathbf{9 3}$ & $\mathbf{3 3 . 7 \%}$ & $\mathbf{8 0 0 - 1 2 0 0}$ \\
\hline Severe & $\mathbf{6 7}$ & $\mathbf{2 4 . 3 \%}$ & $>\mathbf{1 2 0 0}$ \\
\hline Total & $\mathbf{2 7 6}$ & $\mathbf{1 0 0 . 0 \%}$ & \\
\hline
\end{tabular}

Table5. Degree of infection of GI nematodes with different risk factors

\begin{tabular}{|c|c|c|c|c|c|c|}
\hline & \multicolumn{6}{|c|}{ Degree of infection } \\
\hline $\begin{array}{l}\text { Risk } \\
\text { Factors }\end{array}$ & Classifications & $\operatorname{Light}(\%)$ & Moderate(\%) & Severe(\%) & $\chi^{2}$ & P-value \\
\hline \multirow[t]{3}{*}{ Species } & Goat & 29(46) & $15(23.8)$ & 19(30.2) & \multirow[t]{2}{*}{11.436} & \multirow[t]{2}{*}{0.010} \\
\hline & Sheep & $87(40.8)$ & $78(36.6)$ & $48(22.5)$ & & \\
\hline & Total & $116(42)$ & 93(33.7) & $67(24.3)$ & & \\
\hline \multirow[t]{3}{*}{ Age } & Adult & $69(40.4)$ & $66(38.6)$ & 36(21.1) & \multirow[t]{2}{*}{5.583} & \multirow[t]{2}{*}{0.134} \\
\hline & Young & $47(44.8)$ & $27(25.7)$ & $31(29.5)$ & & \\
\hline & Total & $116(42)$ & 93(33.7) & 67(24.3) & & \\
\hline \multirow[t]{3}{*}{ Sex } & Female & 97(43.5) & 75(33.6) & 51(22.9) & \multirow[t]{2}{*}{2.592} & \multirow[t]{2}{*}{0.001} \\
\hline & male & $19(35.8)$ & $18(34)$ & $16(30.2)$ & & \\
\hline & Total & $116(42)$ & 93(33.7) & 67(24.3) & & \\
\hline \multirow[t]{4}{*}{$\mathrm{BCS}$} & Poor & 20(15.6) & $60(46.9)$ & $48(37.5)$ & \multirow[t]{3}{*}{87.856} & \multirow[t]{3}{*}{0.001} \\
\hline & Medium & 34(48.6) & $20(28.6)$ & $16(22.9)$ & & \\
\hline & Good & $62(79.5)$ & $13(16.7)$ & 3(3.8) & & \\
\hline & Total & $116(42)$ & 93(33.7) & $67(24.3)$ & & \\
\hline
\end{tabular}

This study has shown that parasite load is highly related to the body condition of the animals and the difference was statistically significant $(\mathrm{P}<0.05)$ (Table 5). This can be shown by the fact that severely affected animals were high in numbers with poor body conditioned as compared to medium and good body conditioned animals. In this study it had also been tried to see difference in the degree of EPG between young and adult sheep and goats. However the result indicates that there was no statistically significant difference $(\mathrm{P}>0.05)$ between the two age groups. As well the study revealed that, sex had no significant association with EPG ( $>0.05)$ (Table 5).

\section{DISCUSSION}

Many research findings showed that gastrointestinal nematodes are the major causes of losses in production and productivity of small ruminant production in Ethiopia [15].The present study revealed the presence of GIT nematode parasites with an overall prevalence of $71.88 \%$ in sheep and goats. Even the result was relatively higher than the reports of other researchers $[27,28,29]$ who reported $54.1 \%$, $47.67 \%$ and $43.2 \%$ prevalence, respectively. The current finding is also slightly greater than the prevalence of $59.89 \%$ and $68.1 \%$ reported by $[30,31]$ from different parts of Ethiopia respectively. But the finding was lower as compared to the findings of $[18,20]$ who reported the prevalence $88.8 \%$, and $86.7 \%$ from different parts of Ethiopia, respectively.

In contrast, as compared to other findings such as [32] with a prevalence of $96.5 \%$, in central high land, [33] of $91 \%$ in wollaytaSoddo and [33] of $92 \%$ in kombolcha, North Ethiopia, the current study resulted lower prevalence. These relative differences in prevalence of nematode 
parasites may arise due to existence of different climatic or environmental factors that could support survival and development of infective larval stage of most nematodes $[34,35]$.

Prevalence of GI nematode with regard to species in the present study was $75.8 \%$ and $61.2 \%$ in sheep and in goats respectively. These is relatively close with previous observation reported by [20] $89.2 \%$ in sheep and $88.4 \%$ in goats, [36] who reported $85.25 \%$ in sheep and $85.05 \%$ in goats around Haramaya town. On the other hand this study disagree with the reports of [29] who reported prevalence $41.49 \%$ from sheep and $49.2 \%$ from goats and [19] who reported prevalence $68.4 \%$ in sheep and $70.7 \%$ in goats, respectively.

Even though no statistically significant difference was observed in the present study, higher prevalence and EPG count of nematode parasites were observed in sheep than in goats. These results agreed with the report of [38] and could be due to the grazing habit of the sheep which graze closer to the ground fostering opportunity of exposure to parasites. However, these finding was completely disagree with $56.6 \%$ in sheep and 60\% in goat [27] and $97.03 \%$ in sheep and $100 \%$ in goat [10] from Western and Eastern parts of Ethiopia, respectively.

The common nematodes on the study area were $54.17 \%$ Strongyletype, $8.33 \%$ Strongloides, $3.13 \%$ Trichuris, and $6.25 \%$ mixed nematode infections in both sheep and goats. These results slightly agrees with previous studies conducted in different parts of Ethiopia such as 56.6\% Strongyles, $8.2 \% \quad$ Strongyloidesand $5 \%$ Trichuris in Debrezeit[39]. This study revealed that the major infections were with strongyles among the small ruminants (sheep and goats).This finding also agree with several studies conducted so far $[27,31,39]$ who reported high proportion of strongyle infection. This might be due to the fact that ruminants have different level of resistance for different species of parasitic infections [13].

The prevalence of Trichuris species in the present study was $3.13 \%$ and this finding was in agreement with earlier findings $[40 ; 27 ; 31]$ who reported a prevalence of $3.3 \%, 4.5 \%$ and $3.7 \%$, respectively. However, the current finding of Trichuris was lower as compared to $30.3 \%$ from Eastern part of Ethiopia by [10].
In the present study the prevalence of GIT nematodes were analyzed but resulted no statistically significant differences $(\mathrm{P}>0.05)$ between both sex groups. The absence of significant association between sexes with respect to prevalence is coherent with previous reports of $[27,41]$. This indicated that male and female sheep have equal chance of infection if they are exposed to the same contaminated communal grazing pasture. However, [28] reported that female animals are more susceptible to parasitism. It is assumed that females are more prone to parasitism especially during pregnancy and peri-parturient period due to both stress and decreased immune status [42].

Prevalence of nematode with regard to age in the present study was $72.9 \%$ in young and $71.3 \%$ in adult without statistically significant difference. This finding agrees with other studies carried out in Northern Gondar, Ethiopia in which significant association was not observed in age [43].

A significant difference was observed in prevalence of GIT nematode infection in relation to body condition (BCS) such that shedding of nematodes eggs increased in animals with poor body condition $(77.1 \%)$ compared to animals with medium $(70 \%)$ and good body condition (66.1\%) $(\mathrm{P}<0.05)$. Accordingly this result agrees with previous report of $[44,45]$. This finding also revealed that small ruminants with medium and poor body condition score have higher prevalence rate of nematodiasis infection. This might be due to either well-fed animals have good immunity for parasitic infection.

\section{CONCLUSION AND RECOMMENDATIONS}

In the present study, the overall prevalence of gastro intestinal nematodes was $71.88 \%$ both in sheep and goats. The predominant GIT nematodes parasite identified were strongyles, strongyloides and trichuris species. Conclusively gastrointestinal nematodes were prevalent on sheep and goats in ZiwayDugda district affecting the health and productivity of these animals. These parasites affected all different age, sex and body conditions with variable degrees. Furthermore, weak status of animal health services complementing with lack of proper management, practice of mixed farming leads to communal grazing with many species of animals. As animal owners give the first line to draught animals; sheep and goats mainly forced to graze behind overstocked areas 
Prevalence and Associated Risk Factors of Gastrointestinal Nematodes of Sheep and Goats in ZiwayDugda District, Eastern Arsi Zone of Oromia Regional State, Ethiopia

which lead them to graze close to the ground and on fecal materials, causing in the uptake of higher numbers of infective larvae. Put together, the finding suggests that ZiwayDugda district is favorable for the continual maintenance and successive transmission of helminthes parasites to vulnerable hosts. Many animals were subclinically infected without noticing awareness to farmers for selecting strategic control and prevention measures. So depending on the above conclusions the following recommendations were forwarded:

- Awareness creation should be conducted for animal owners and other stake on regular de worming of sheep and goats.

- Provision of well management, adoption of intensive farming and interspecies mixing of animals.

- Definitive diagnosis should be conducted by clearly isolating and identifying parasitic infection through coprological examination in the study area.

- Further study should be carried out on the efficacy and the anthelminthic resistance

- Epidemiological study should be conducted to promote sustainable, effective, strategic and prevention of nematode infection in sheep and goats.

\section{ACKNOWLEDGEMENT}

The authors would like to thank wollega university school of veterinary medicine for technical support during sample processing. Much of the acknowledgement also goes to ZuwayDugdaDistrict Bureau of Agriculture and Veterinary clinic aswell as their corresponding staffs for their cooperations and unreserved technical and material support in this research work.

\section{REFERENCES}

[1] Yayneshet, T. (2010): Feed resource availability in Tigrai Region, Northern Ethiopia, for Production of Export Quality Meat and Livestock.PHD Dessertation, Mekelle University, Ethiopia.

[2] Kefyalew, A and Tegegne, F. (2012): The effect of climate change on ruminant livestock population dynamics in Ethiopia. Bahir Dar University, college of agriculture and environmental sciences, department of animal production and technology, Bahir Dar, Ethiopia and Mizan-Tepi University, college of agriculture and natural resources, department of animal sciences, Ethiopia, Livestock Research for Rural Development, Pp: 24(10).

[3] Park, Y; Haenlein, G (Eds.). (2006): Handbook of Milk of Non-Bovine Mammals. Blackwell Publishing, Ames, Iowa, USA/Oxford, UK, Pp: 449.

[4] Morgan, E; Charlier, J; Hendrickx, G; Biggeri, A; Catalan, D; von Samson-Himmelstjerna, G;Demeler, J; Müller, E; van Dijk, J; Kenyon, F; Skuce, P; Höglund, J; O’Kiely, P; van Ranst, B; de Waal, T; Rinaldi, L; Cringoli, G; Hertzberg, H; Torgerson, P; Adrian Wolstenholme, A;Vercruyss, J. (2013): Global Change and Helminth Infections in Grazing Ruminants in Europe: Impacts, Trends and Sustainable Solutions. Agriculture, 3: 484-502.

[5] Tsedeke, K. (2007): Production and Marketing systems of sheep and goats in Alaba, Southern Ethiopia. MSc Thesis, Department of Animal and Range Sciences, Awassa College of Agriculture, School of graduate studies, Hawassa University, Awassa, Ethiopia.

[6] Anonymous. (2005): Agricultural sample survey, volume II Report on livestock and livestock characteristics (Private peasant'holdings). Stasticalbuleetin, Pp: 331.

[7] Food and Agricultural Organization FAO, (1993): Production year book, Rome, Italy, Vol. 46

[8] Perry, B; Randolph, T; McDermott, J; Sones, K and Thornton, P. (2002): Investing in Animal Health Research to Alleviate Poverty. International Livestock Research Institute, Nairobi, Kenya, Pp: 148.

[9] Biffa, D; Jobre, Y and Chakka, H. (2007: Ovine helminthosis, a major health constraint to productivity of sheep in Ethiopia. Animal Health Research Reviews, 7(1/2), Pp: 107-118. doi:10.1017/ S146625 2307001132.

[10] Abebe, W and Esayas, G. (2001): Survey of ovine and caprine gastro-intestinal helminthosis in Eastern part of Ethiopia during the dry season of the year Revue Méd. Vét. 152, Pp: 379-384.

[11] Sissay, M; Uggla, A and Waller, P. Epidemiology and seasonal dynamics of gastrointestinal nematode infections of sheep in a semi-arid region of eastern Ethiopia. Veterinary Parasitology, 2007a: 143: Pp: 311321.

[12] Soulsby, L. (1986): Helminthes, arthropods and protozoa of domestic animals 7 th ed. London, UK: Bailliere Tindall. Pp: 247-250.

[13] Urquhart, G; Armour, J; Duncan, J; Dunn, A and Jennings, F. (1996): Veterinary Parasitology, 2 ed. Blackwell Science, United Kingdom; Pp: 345-45. 
[14] Kaplan, M. (2006): Update in parasite control in small ruminants: Addressing the challenges posed by multiple-drug resistant worms. In Proceeding of the American Association of Bovine practioners, Saint Paul, MN, USA, September 21-23.

[15] Demelash, B; Yilma, J; and Hassen, C. (2006): Ovine Helminthosis is major health constraints to productivity of sheep in Ethiopia. DVM Thesis, Faculty of Veterinary Medicine, Awassa University, Awassa, Ethiopia.

[16] Food and Agriculture Organization FAO, (2002): Biological control of nematode parasites of small ruminants in Asia. FAO Animal Production and Health Paper, Pp: 1100.

[17] Hansen, J and Perry, B. (1994): The epidemiology, diagnosis and control of helminth parasites of ruminants. International Laboratory for Research on Animal Diseases (ILRAD), Nairobi (Kenya). $2^{\text {nd }} E d$ : Pp: 171.

[18] Shankute, G; Bogale, B; Melaku, A. (2013): An Abattoir Survey on Gastrointestinal Nematodes in Sheep and Goats in Hemex-Export Abattoir, Bishoftu (DebreZeit), Central Ethiopia. J. Adv. Vet. Res (3). Pp: 60-63.

[19] Dilgasa, L; Biruhtesfa, A and Surafel, K. (2015): Prevalence of Gastrointestinal Nematodes of Small Ruminants in and Around ArsiNegele Town, Ethiopia. AmericanEurasian Journal of Scientific Research 10 (3): 121-125.

[20] Mideksa, S; Mekonnen, N and Muktar, Y. (2016): Prevalence and Burden of Nematode Parasites of Small Ruminants in and Around Haramaya University. World Applied Sciences Journal.34(5): Pp: 644-651.

[21] Getachew, M; Tesfaye, R and Sisay, E. (2017): Prevalence and Risk Factors of Gastrointestinal Nematodes Infections in Small Ruminants in Tullo District, Western Harerghe, Ethiopia. Journal of Veterinary Science and Technology, 8:2.

[22] ZuwayDugda District Agricultural Development Beureau (ZDDADB), 2016. Annual report Pp. 58.

[23] Thrusfield, M. (2007): Veterinary Epidemiology. Blackwell Science Limited, USA, Pp: 180-181.

[24] Kumsa, B; Tadesse, T; Sori, T; Duguma, R and Hussen, B. (2010): Helminths of sheep and goats in Central Oromia (Ethiopia) during the dry season. J. Anim. Vet. Adv. 10:1845-1849.

[25] Kripali, K; Rajput, S; Jitendra, V; Shivan, V and Pritee, G. (2010): Prevalence of helminthes in small ruminants in Tarai region of Uttarakhand. Veterinary World,2: Pp: 265-266.
[26] Soulsby, L. (1982): Helminths, Arthropods and Protozoa of Domesticated Animals. 7th ed., London: BailliereTindall. Pp: 119-127.

[27] Regassa, F; Sori, T; Dhuguma R and Kiros Y. (2006): Epidemiology of Gastrointestinal Parasites of Ruminants in Western Oromia, Ethiopia, International Journal of Applied Research Veterinary Medicine, 4(1): Pp: 51-57.

[28] Dagnachew, S; Amamute, A;Temegen, W. (2011): Epidemiology of gastrointestinal helminthiasis of small ruminants in selected sites of North Gondar zone, Northwest Ethiopia.Ethiopian Veterinary Journal, 15: 5768.

[29] Muluneh, J; Bogale, B and Chanie, M. Major Gastrointestinal Nematodes of Small Ruminants in Dembia District, Northwest Ethiopia. European Journal of Applied Sciences, 2014; 6(2): 30-36.

[30] Zerihun, T. (2012): Helminthosis of sheep and goats in and around Haramaya, Southeastern Ethiopia. Journal of Veterinary Medicine and Animal Health, 4: Pp: 48-55.

[31] Diriba, L and Birhanu, A. (2013): Prevalence of ovine gastrointestinal nematodes in and around Asella, South Eastern Ethiopia Asella Regional Veterinary Laboratory P. O. Box 212, Asella, Ethiopia. Journal of Veterinary Medicine and Animal Health. Pp: 223-228.

[32] Amenu, G. (2005): Epidemiology of GIT nematode of small ruminants in different agroecological zone of central high lands of Ethiopia. Agricultural sample survey, volume II. Report on Livestock and Livestock characteristic, Ethiopia. Statistical bulletin, Pp: 331.

[33] Dereje, W. (1992): Investigation of common GI parasite of small ruminants in and around WollaytaSoddo. DVM thesis, AAU, FVM, DebreZeit Ethiopia.

[34] Genene, R. (1994): Study on prevalence of Ovine gastrointestinal helminthes in and around, Kombolcha DVM thesis, AAU, FVM, DebreZeit, Ethiopia.

[35] Assefa, D and Sissay, L. (1998): Preliminary investigation on seasonal occurrence of parasites around sheno. In fifth national conference of society of animal production. ESAP. Addis Ababa, Ethiopia, Pp: 128-137.

[36] Andrews, S. (1999): The life cycle of Fasciola hepatica. In: J.P. Dalton (ed) Fasciolosis. CAB, Wallingford, Pp: 1-29.

[37] Dugasa. (2010): Prevalence of nematode parasite in eastern Ethiopia around Haramaya town DVM thesis.

[38] Kumsa, B and Wossene, A. (2006): Abomasal nematodes of small ruminants of Ogaden region, eastern Ethiopia, prevalence, worm 
Prevalence and Associated Risk Factors of Gastrointestinal Nematodes of Sheep and Goats in ZiwayDugda District, Eastern Arsi Zone of Oromia Regional State, Ethiopia

burden and species composition, Revue Med. Vet, 157(12): 27-32.

[39] Tigist, T. (2008): Gastrointestinal parasitosis of small ruminants in and around DebreZeit.DVM thesis HU, FVM, Haramaya, Ethiopia.

[40] Temesgen, T. (2008): Study on prevalence of ovine gastrointestinal parasite in and around Bedele DVM thesis, HU, FVM, Haramaya, Ethiopia.

[41] Keyyu, J; Kassuku, A; Msalilwa, L; Monrad, J and Kyusgaard, N. (2006): Cross sectional prevalence of helminth infections in cattle on traditional, small scale and large-scale dairy farms in Iringa district,Tanzania. Veterinary Research Communications, 30: 45-55.

[42] Gauly, M; Schackert, M; Hoffmann, B and Erhardt, G. (2006): Influence of sex on the resistance of sheep lambs to an experimental Haemonchuscontortus infection. Dtsch. Tierarztl. Wochenschr, 113: 178-181.

[43] Shimelis, D; Asmare, A and Wudu, T. (2011): Epidemiology of gastrointestinal helminthiasis of small ruminants in selected sites of North Gondar Zone, northwest Ethiopia.Ethiop. Vet. J., 15(2): Pp: 57-68.

[44] Tesfaheywet, Z. (2012): Helminthosis of sheep and goats in and around Haramaya, southeastern Ethiopia, Journal of Veterinary Medicine and Animal Health,4: Pp: 48-55.

[45] Nigatu, K. (2008): Gastrointestinal Helminthosis of Sheep in Awi Zone, northwestern Ethiopia Global Veterinaria, 12: 121-129.

Citation: Jiregna Dugassa, Abdela Hussein, Abriham Kebede, Chala Mohammed. Prevalence and Associated Risk Factors of Gastrointestinal Nematodes of Sheep and Goats in ZiwayDugda District, Eastern Arsi Zone of Oromia Regional State, Ethiopia. ARC Journal of Animal and Veterinary Sciences. 2018; 4(2):6-18. doi: dx.doi.org/ 10.20431/2455-2518.0402002.

Copyright: (C) 2018 Authors. This is an open-access article distributed under the terms of the Creative Commons Attribution License, which permits unrestricted use, distribution, and reproduction in any medium, provided the original author and source are credited. 